\title{
Tres modelos de explicación de la refracción: Bacon, Pecham, Witelo
}

\author{
Three models of explanation of refraction: \\ Bacon, Pecham, Witelo
}

\author{
Carlos Alberto Cardona SuÁrez ${ }^{1}$ \\ Universidad del Rosario (Bogotá-Colombia)
}

Recibido: 01-03-2011

Aceptado: 04-04-2012

\section{Resumen}

El artículo examina tres propuestas de explicación del fenómeno de refracción de la luz formuladas por los pensadores medievales Roger Bacon, John Pecham y Erazmus Ciolek Witelo. Se muestra, en el caso de Bacon, que la explicación estaba soportada en una metafísica de la propagación de los poderes causales y anidaba un conflicto insalvable. En el caso de Pecham se muestra un mayor compromiso con la necesidad de una ley cuantitativa que, desafortunadamente, conduce a una explicación frustrada. Finalmente, se valora el deseo de Witelo por introducir elementos cosmológicos en su explicación.

Palabras clave: Especies, Luz, Opus majus, Perspectiva, Refracción.

\begin{abstract}
This paper examines three explanations of the light refraction proposed by the medieval thinkers Roger Bacon, John Pecham and Erazmus Ciolek Witelo. It is shown, first, that Bacon's explanation was supported in a metaphysics of the multiplication of causal powers and, second, this explanation arrives to an insurmountable conflict. In the case of Pecham, it is shown that there is a greater commitment with a quantitative law which, unfortunately, leads to an defeated

\footnotetext{
${ }^{1}$ Agradezco los comentarios de Sebastian Cristancho y Nicolas Montenegro. Agradezco también al Fondo de Investigaciones de la Universidad del Rosario (FIUR) por el apoyo prestado.
} 
explanation. Finally, the desire of Witelo to introduce cosmological elements in its explanation is valued.

Keywords: Light, Opus majus, Perspective, Refraction, Species.

\section{Introducción}

Hoy en día ya no resulta popular una actitud prevenida con respecto a los escritos científicos de autores de los siglos XII o XIII. Ya no tenemos por qué verlos como la expresión de errores dramáticos o de acercamientos ingenuos que fueron corregidos por las mentes preclaras de los siglos XVII y siguientes. Este eclecticismo saludable tampoco tiene por qué llevarnos a pensar que lo valioso de los escritos científicos de los siglos XII y XIII reside en que anticiparon las orientaciones de la ciencia moderna. ${ }^{2}$ En cualquiera de los dos extremos corremos el riesgo de sacrificar los acercamientos originales de los autores de dichos siglos, por hacerlos gravitar en torno a los centros ideológicos del lector contemporáneo.

Los relatos asociados con el surgimiento de la ciencia moderna se han encargado de sublimar los debates en torno a la astronomía y a los estudios del movimiento. Nadie pretende desconocer la importancia de dichos debates. No obstante, dicha actitud llevó a invisibilizar otras controversias de similar envergadura; por ejemplo, los debates asociados con la percepción. Afortunadamente la situación ha venido cambiando y hoy es mayor el número de trabajos que se ocupan del protagonismo de los estudios de la percepción en la consolidación de la modernidad. Los estudios medievales asociados con la percepción visual fueron edificando lentamente algunas condiciones básicas para la consolidación del discurso autodenominado Ciencia Moderna. Tanto los trabajos del filósofo y científico árabe Alhacén, como los trabajos del filósofo franciscano Roger Bacon determinaron el horizonte de la discusión relacionada con los avatares de la percepción visual. No se trata, sin embargo, de proponer una estricta continuidad entre ciencia medieval y ciencia moderna; sin duda hay rasgos de mayor distanciamiento que cercanía. Los estudios relacionados con la percepción visual contribuyeron a (i) someter un campo de estudio a la matematización completa, (ii) ofrecer un espacio abierto de posibilidades para la evaluación experimental de nuevas conjeturas, (iii) desarrollar nuevos instrumentos para la exploración científica; (iv) afianzar el distanciamiento entre el mundo físico y el mundo mental, toda vez que se fortaleció la creencia según la cual el sensorio contempla imágenes que no pueden reducirse a fenómenos de naturaleza física.

${ }^{2}$ Cfr. A. C. Crombie. Robert Grosseteste and the origins of experimental science 1100-1700. Oxford: Oxford at the Clarendon Press, 1953. 
El estudio de la luz concitó la atención de varios pensadores medievales en buena medida gracias a las metáforas y asociaciones que se establecieron con Dios, el creador. Este interés también se vio motivado por la traducción al latín de clásicos griegos (Euclides, Aristóteles, Galeno), por la traducción de textos árabes (Al Kindi, Alhacén) y por el auge de concepciones neoplatónicas. La óptica medieval tenía un espectro amplio de preocupaciones: (i) naturaleza de la luz, (ii) elucidación de la percepción visual (lo que exige ocuparse, entre otras cosas, de exploraciones anatómicas y fisiológicas), (iii) naturaleza del color (especial fascinación producía el estudio del arco iris), (iv) formación de imágenes en espejos planos, esféricos, cónicos y cilíndricos (Catóptrica), (v) refracción de la luz.

Todas las agendas relacionadas con el estudio de la percepción visual contemplaban la necesidad de elucidar en forma completa los fenómenos asociados con la refracción de la luz; toda vez que la información visual que viene del exterior, siempre que asumamos una posición intramisionista, abandona el desplazamiento rectilíneo cuando tiene que atravesar las diferentes cavidades y humores del ojo. Johannes Kepler, por ejemplo, se ocupó cuidadosamente de estudiar la refracción de la luz esperando con ello encontrar métodos para corregir la información que podía acopiarse a propósito de los objetos celestes. En efecto, la luz que viene de dichos objetos ha de refractarse al pasar del medio celeste al aire y al atravesar también las esferas cristalinas que constituyen el globo ocular. A pesar de los esfuerzos cuidadosos, Kepler no logró llegar a una ley precisa para la refracción de la luz.

Los estudios acerca de la refracción de la luz (o de las especies) contemplan dos elementos esenciales: de un lado, la necesidad de hallar una ley cuantitativa que estipule el comportamiento de la luz; y, de otro lado, hallar una explicación cualitativa plausible que dé cuenta del abandono del desplazamiento rectilíneo de la luz cuando cambia de un medio a otro. David C. Lindberg ha criticado con razón a los historiadores de la ciencia premoderna y medieval por concentrar sus esfuerzos en elucidar los caminos que condujeron al descubrimiento de la ley que expresa las regularidades matemáticas de la refracción, mientras relegan a un segundo nivel de importancia las discusiones en torno a las causas de la refracción. ${ }^{3}$ En el presente artículo nos ocuparemos de tres modelos de explicación cualitativa de la refracción. Nos referimos a los modelos de Roger Bacon, John Pecham y Erazmus Ciolek Witelo. Mostraremos que (i) Bacon vacila entre dos hipótesis de trabajo que no se concilian fácilmente; (ii) Pecham critica el finalismo de Bacon, intenta substituir el principio de conservación de Bacon por un principio que establezca la invarianza de una cantidad matemática, pero fracasa a la hora de hacer explícita dicha cantidad. En ese orden de ideas, abandona el finalismo de Bacon, pero lo sustituye con una

${ }^{3}$ Cfr. David C. Lindberg. "The cause of refraction in medieval optics". En The British Society for the History of Science, Vol. 4, No. 1, 1968, p. 23. 
explicación frustrada; (iii) Witelo, por su parte, concentra su atención en suprimir el protagonismo de la luz para cedérselo a ciertas fuerzas cósmicas. La propuesta de Witelo pretende dar el protagonismo a cierto tipo de interacción que ha de producirse a lo largo de la línea perpendicular a la interface entre los medios. El estudio de la propuesta de Bacon será más extenso, toda vez que Pecham y Witelo suscriben por completo la metafísica de la multiplicación de las especies propuesta por el filósofo británico.

El comentario acerca del modelo de Bacon se divide en dos partes, primero se defiende la metafísica general de la multiplicación de efectos causales. Esta exposición es el fundamento para la explicación de la refracción toda vez que la propagación de la luz puede concebirse como el paradigma fundamental para la multiplicación de especies. En términos generales, los tres autores comparten ese trasfondo metafísico. En la segunda parte, la exposición se concentra exclusivamente en la refracción de la luz.

\section{Roger Bacon: La multiplicación de las especies}

Tan pronto como Clemente IV (Guy de Foulques) fue nombrado papa en 1265, pidió a Roger Bacon que le hiciera llegar el conjunto de escritos en los que estaba trabajando el filósofo y que contenían, según información que había acopiado el nuevo papa, la síntesis de una reforma general de los planes educativos. ${ }^{4}$ Clemente IV le advirtió que tuviese el mayor sigilo con el encargo para evitar cualquier suspicacia que pudiese poner a Bacon en aprietos en el interior de la orden franciscana. ${ }^{5}$ Bacon acopió varios escritos previos y completó algunos materiales para cumplir con la solicitud. El conjunto enviado al papa contenía: el Opus Majus, el Opus Minus, y De multiplicatione specierum. Clemente IV murió en el año 1268 sin dejar una clara evidencia de haberse ocupado de los escritos de Bacon. Unas crónicas escritas casi un siglo después de la muerte de Bacon aseguran que gracias al testimonio de algunos frailes franciscanos, quienes condenaron las enseñanzas de Bacon por contener novedades sospechosas, el filósofo fue condenado a alguna forma de reclusión. ${ }^{6}$

\footnotetext{
${ }^{4}$ Bacon tenía una propuesta orientada a reformar la educación en el mundo cristiano (Cfr. J. Hacket. "Roger Bacon: his life, career and works". En HACKET J. (edit.). Roger Bacon \& the Sciences. Commemorative Essays. Leiden: Brill, 1997 p. 17). A propósito de los motivos para una reforma urgente de los planes de formación véase L Thorndike. "The True Roger Bacon, I". En The American Historical Review, Vol. 21, No. 2, 1916.

${ }^{5}$ Cfr. B. Clegg. The first scientist. A life of Roger Bacon. New York: Carroll \& Graff Publishers, 2003 p. 96.

${ }^{6}$ A propósito de los motivos del arresto domiciliario véase L. Thorndike. "The True Roger Bacon, II". En The American Historical Review, Vol. 21, No. 3, 1916, pp. 471-474. Véase también la reacción de
} 
El Opus Majus es un compendio de siete partes, a saber: (i) Causas del error, (ii) Filosofía, (iii) Estudio de las lenguas, (iv) Matemáticas, (v) Perspectiva, (vi) Ciencia experimental, (vii) Filosofía moral. En la cuarta parte (Matemáticas) se pretende defender que las matemáticas son, en primer lugar, la puerta de entrada a las ciencias particulares y, además, el seguro firme que evita el asalto del error. En palabras de Bacon: «[E]l conocimiento de esta ciencia prepara la mente y la eleva hacia cierto conocimiento de todas las cosas, asi que alguien que aprende las raices del conocimiento de este entorno y las aplica correctamente al conocimiento de otras ciencias y asuntos, será capaz de conocer, fácilmente y en forma efectiva, todo lo que se sigue sin error y duda». ${ }^{7}$ Ver en las matemáticas la referencia central para el desarrollo de la filosofía natural es, sin duda, una herencia recogida en la obra de Grosseteste. Así introduce Grosseteste su breve tratado acerca de la líneas, los ángulos y las figuras: «La utilidad de considerar las líneas rectas, los ángulos y las figuras es muy grande, dado que es imposible entender la filosofía natural sin ellas», y más adelante continua: «[T]odas las causas de efectos naturales deben ser expresadas por medio de líneas rectas, ángulos y figuras, pues de otra manera resulta imposible comprender su explicación». ${ }^{8}$ El carácter protagónico que se le pretende asignar a la matemática es una novedad para el mundo latino occidental del siglo XIII. Este hecho se fue gestando en el siglo XII gracias a las traducciones al latín de algunas obras atribuidas a Euclides, entre ellas la óptica y la catóptrica, y a la traducción de la óptica de Ptolomeo. También aparecieron versiones en latín del De Aspectibus de Alkindi y el De Aspectibus de Alhacén.

Bacon reconoce e insiste con vehemencia que hay dos métodos de prueba cuando se trata de las cosas de la naturaleza. Una demostración que procede, por vía silogística, desde las causas hasta los efectos (propter quid), y otra argumentación que se aventura desde los efectos tratando de fijar las causas (quia). La primera, cree Bacon, es más poderosa que la segunda. «La demostración causa que la verdad sea conocida» sostiene Bacon y ello se debe a que es posible tener un ejemplo, provisto por las figuras, que puede ser percibido sensorialmente de la misma manera que ocurre con las manipulaciones de prueba hechas sobre las figuras. ${ }^{9}$ Es este tipo de ejercicio el que nos permite salir de dudas cuando ellas nos asalten. Las ciencias que no pueden hacer uso de las matemáticas están condenadas a cargar por siempre con la incertidumbre.

\footnotetext{
P. Sidelko a la tesis de Thorndike en P. Sidelko. "The comdemnation of Roger Bacon". En Journal of Medieval History, Vol. 22, No. 1, 1996, pp. 69-81.

${ }^{7}$ R. Bacon. Opus majus. Philadelphia: University of Pennsylvania Press, 1928, IV, dist. 1, cap. 1, p. 116. En las referencias al Opus majus, haremos mención al libro, a la parte del libro cuando haya lugar, a la distinción cuando sea el caso, al capítulo y a la página de la edición preparada por Robert Burke.

${ }^{8}$ Cfr. R. Grosseteste. "Concerning Lines, Angles, and Figures". En GRANT, E. (editor). A Source Book in Medieval Science. Cambridge (Mass): Harvard University Press, 1974, p. 385.

${ }_{9}$ Opus majus, IV, dist. 1, cap. 3, p. 124
} 
En la parte V (Perspectiva), Bacon pretende ofrecer un completo estado del arte de las investigaciones en este campo. Bacon usa la palabra Perspectiva para referirse a los estudios de la luz, el color y la visión en general. Sus fuentes son absolutamente claras: Aristóteles, Euclides, Ptolomeo, Avicena, Tideus, Alkindi y, de manera muy especial, Alhacén. Creo que no hay mayor injusticia si evaluamos la Perspectiva de Bacon como una breve presentación en occidente de la obra de Alhacén, enriquecida con la influencia neoplatónica de la obra de Grosseteste. ${ }^{10}$ Mark Smith, en la presentación que hace del volumen V de la obra de Witelo, señala, con justa razón, que la principal debilidad de la obra de Alhacén reside en la manera como la superestructura fenoménica arroja sombras sobre el trasfondo filosófico propio de los fundamentos metafísicos de la nueva perspectiva. Esta laguna, según Smith, vino a llenarse con la insistencia metafísica de Bacon: «Fue Roger Bacon más que cualquier otro pensador medieval quien hizo explícitas aquellas asunciones tácitas [los presupuestos metafísicos], formando de ellas una justificación teórica completa que tomó forma en la doctrina de la "multiplicación de las especies" "». ${ }^{11}$

En la parte VI (Ciencia experimental), Bacon sostiene en forma taxativa que: «[S]in la experiencia nada puede ser suficientemente conocido. Hay dos modos de adquirir el conocimiento, esto es, por razonamiento y por experiencia. El razonamiento extrae una conclusión y nos la garantiza, pero no hace que la conclusión sea cierta, ni remueve dudas de tal manera que la mente pueda descansar sobre la intuición de la verdad, a menos que la mente descubra esto por el camino de la experiencia». ${ }^{12}$ Reconocer en forma taxativa la importancia de la experiencia e insistir en ello hasta el cansancio marca una pauta distintiva de los escritos del filósofo inglés. El parágrafo citado muestra que Bacon advierte con claridad que el razonamiento por sí sólo no puede ir más allá de poner en evidencia una conexión analítica entre los dos extremos del razonamiento: las premisas iniciales y la conclusión. Sólo a través de la experiencia podemos romper el círculo analítico que tiende el razonamiento. Bacon se vale de los estudios adelantados en relación con el arco iris para ilustrar detalladamente cómo se puede auxiliar a la mente con un tipo de experiencia controlada. ${ }^{13}$

\footnotetext{
${ }^{10}$ En las referencias a la parte $\mathrm{V}$ del Opus majus haremos uso de la traducción reciente preparada por David Lindberg (1996) y nos apartaremos de la traducción que estamos siguiendo para el resto de la obra. Mencionaremos primero el título Perspectiva y a continuación aludiremos, en su orden, a la parte, la distinción, el capítulo y las líneas de la edición en latín.

${ }^{11}$ Cfr. A. M. Smith. Witelonis perspectivae liber quintus. Book $V$ of Witelo's Perspectiva. Wroclaw: Studia Copernicana XXIII, The Polish Academy of Science Press, 1983, pp. 28-29.

12 Opus majus, VI, cap. 1, p. 583.

${ }^{13}$ Lindberg sostiene con poderosas razones que los tratados de perspectiva de Bacon no se destacan precisamente por la actividad empírica originalmente desarrollada por el filósofo. La mayoría de montajes aludidos proviene o bien de la obra de Alhacén o de la obra de Ptolomeo. Cfr. D. Lindberg, "Light, Vision and the Universal Emanation of Force", en J. HACKET, 1997b, pp. 243-275. Se puede
} 
De multiplicatione specierum formaba parte, junto con el Opus majus y el Opus minus, del paquete de documentos que Bacon hizo llegar al papa Clemente IV. Bajo el título general de la Multiplicación de las especies Bacon quiere dar cuenta de los procesos mediante los cuales un agente adelanta una acción que provoca una transformación en un receptor. La obra, entonces, pretende elucidar los mecanismos de transferencia de los poderes causales. El trasfondo general ha de aportar los elementos de juicio para considerar el proceso mediante el cual un objeto está en condiciones de provocar la aparición de un simulacro suyo en nuestro campo visual. A diferencia de Alhacén, Bacon no cree que el estudio de la perspectiva se justifique por sí mismo. Al contrario, como sostiene M. Smith, ${ }^{14}$ Bacon, siguiendo a Grosseteste, cree que el estudio de la perspectiva puede arrojar luces acerca del orden metafísico del mundo. En otras palabras, el estudio de la luz puede ofrecer la clave para entender el proyecto y la fuerza creadora de Dios.

Con el término especie el autor se refiere al primer efecto que produce cualquier cosa que actúa naturalmente. ${ }^{15}$ La palabra alude, pues, a la propagación de la fuerza en múltiples direcciones. Este término resulta emparentado con los siguientes: (i) semejanza del agente, (ii) imagen, para referirse a la similitud del agente con su primer efecto; (iii) especie, para aludir, en forma restringida, a los efectos sobre el sensorio o sobre el intelecto; (iv) ídolo, para aludir al efecto sobre un espejo; (v) simulacro, si se quiere pensar en las copias que los objetos generan de sí mismos; (vi) fantasma, para referirse a las apariciones en los sueños, (vii) forma, es el término que emplean Aristóteles y Alhacén; (viii) intención, para aludir al término que algunos pensadores medievales usaban para subrayar el hecho de que aquello que hace las veces de un simulacro de un objeto en el sensorio, tiene una forma de existencia más débil que la del objeto mismo, tal simulacro tiene la forma de una inexistencia; (ix) impresión, cuando se piensa en la figura que usa Aristóteles de un objeto que deja su marca o su huella en una tablilla de cera. En su forma

comparar, por ejemplo, los experimentos sugeridos por Bacon en (Perspectiva, II, dist. 2, cap. 3) con los descritos por Alhacén (2001, III, 2). A comienzos del siglo XX se desató un debate profundo acerca del verdadero o del aparente método experimental de Bacon. Mientras Whewell sostenía posiciones optimistas, Duhem y Thorndike se encargaron de arrojar serias dudas al respecto. Más tarde, Crombie resucitó las posibilidades de ver en la obra de Bacon un antecedente de los métodos modernos de la ciencia. Una síntesis completa del debate se encuentra en J. Hackett, "Roger Bacon on Scientia Experimentalis", en J. HACKETT, 1997b, pp. 277-315.

${ }_{14}$ Cfr. A. M. Smith, 1983, p. 42.

${ }^{15}$ Cfr. Multiplicatione, I, cap. 1, 28-29. Las referencias a De multiplicatione specierum se harán de la siguiente manera: se enuncia el título Multiplicatione seguido de la parte en números romanos, el capítulo en números arábigos y, a continuación, la (o las) línea(s) correspondiente(s) a la edición en latín. Usaremos la edición preparada por Lindberg: D. C. LINDBERG (editor), 1998. Roger Bacon's Philosophy of Nature. A critical edition, with English translation of De multiplication specierum and De speculis comburentibus. South Bend (Ind): St. Augustine's Press. 
original el término species significaba aspecto, forma o apariencia exterior. ${ }^{16}$ Aludir a la causalidad ha de llevarnos a elucidar la manera como un objeto procura crear copias o simulacros suyos alrededor. En ese ejercicio de multiplicación, los objetos emulan, en un grado absolutamente inferior, la potencialidad creadora de Dios. La propagación radiante de la luz ofrece el paradigma esencial para la multiplicación de los efectos causales.

La intención básica de Bacon es mostrar que las especies (simulacros) son similares en esencia y definición al agente que las genera. El soporte para la demostración deviene principalmente de las doctrinas sostenidas por Aristóteles en el tratado Acerca de la generación y la corrupción y de la influencia neoplatónica recogida en la dinámica radiante de Grosseteste. Quien ha de recibir una acción ha de ser diferente inicialmente al agente; en tanto que a través de la acción llega a serle, en algún sentido, semejante. Cuando un agente provoca una alteración en un receptor, lo hace como si estuviera animado por una causalidad final: provocar un simulacro de sí mismo. Si un agente causal $A$ obra sobre un receptor $B$, hemos de esperar que los efectos producidos en $B$ ya tuviesen alguna forma de existencia en $A$. No puede existir un efecto que se produzca desde la nada. En ese orden de ideas, si la especie del color pudiese ser un color que le es semejante, tendríamos argumentos poderosos para sostener la objetividad de nuestra aprehensión perceptiva de los objetos coloreados. Para decirlo en un lenguaje que no le es propio a Bacon, tendríamos argumentos para pensar que la aprehensión de ciertas especies (en este caso el color) da cuenta de algunas cualidades primarias del objeto percibido. ${ }^{17}$

Podemos sentirnos inclinados a creer que la multiplicación de la fuerza implica solamente la transferencia de ciertas afecciones que residen a la manera de accidentes; así como un objeto caliente radia su calor a los objetos vecinos. Bacon, no obstante, insiste en que la multiplicación de las especies se da también al nivel de las sustancias. Tres son los argumentos básicos que exhibe el autor. En primer lugar, dado que la sustancia es más noble que el accidente, y es claro que este último puede replicar especies suyas, hemos de esperar que, con mayor razón, la sustancia haga lo propio. Así mismo, dado que la sustancia puede llegar a su ser en virtud de un proceso de generación, y la cosa generada no puede devenir de un agente que le resulte inferior, en consecuencia, la naturaleza sustancial no podría generarse a partir de meros accidentes. Por último, las formas accidentales no pueden ser generadas en algo salvo que el sujeto propio sea, así mismo, generado primero por naturaleza. En otras palabras, el accidente no puede existir sin su sujeto propio; así entonces, si el calor (en calidad de accidente) es capaz de generar una especie suya, esta especie, a su turno, debe ser el accidente de su sujeto propio; en consecuencia, el sujeto

\footnotetext{
${ }^{16}$ Cfr. P. Michaud-Quantin, Études sur le vocabulaire philosophique du moyen âge, Roma: Ed. Dell'Ateneo, 1970, p. 113.

${ }^{17}$ Perspectiva, II, dist. 3, cap. 1, 9-10.
} 
del calor también ha de generar una réplica (especie) suya. Veamos la síntesis de Bacon: «asi como la sustancia es al accidente, asi lo es la especie de la sustancia a la especie del accidente; en consecuencia, de la misma manera como no puede existir el accidente sin la sustancia, no puede darse la especie del accidente sin la especie de la sustancia». ${ }^{18}$

Ahora bien, para nosotros resulta claro que estamos en condiciones de recibir (o ser afectados por) las especies sensibles (concebidas a la manera de especies de accidentes); sin embargo, no resulta claro que seamos igualmente afectados por las especies sustanciales. El argumento metafísico de Bacon parece imponer la existencia de especies sustanciales y la evidencia empírica sugiere que no las percibimos a la manera de especies sensibles. Estos elementos llevan a Bacon a concluir:

«[A]unque la afirmación de que la sustancia produce una especie sensible puede ser extendida a cada agente natural, no obstante esta especie no es sensible por los cincos sentidos exteriores o por el sentido común. Sin embargo, puede ser recibida por el mismo poder de cogitación y estimación por el cual una oveja percibe la especie de la complexión de un lobo cuando esta especie ocupa y perturba el órgano de su poder estimativo» ${ }^{19}$

Estamos ante un muy interesante ejemplo en el que una conclusión metafísica y una demanda epistemológica nos llevan a inferir la presencia de una suerte de entidad. En primer lugar, no hay accidente sin sustancia, las especies de los accidentes deben ser también accidentes, por lo tanto hay especies de sustancias. En segundo lugar, las especies de los sensibles propios nos afectan de tal manera que llegamos a ser conscientes de su afección; sin embargo, no somos conscientes de la afección sensorial de las especies de las sustancias. Por lo tanto, las especies de las sustancias, si bien no afectan nuestros órganos de recepción sensorial, sí dejan su huella en nuestros poderes de cogitación. El argumento también puede leerse al revés: dado que una suerte de razonamiento metafísico me impone que no hay accidente sin sustancia y la especie de un accidente es, a su turno, un accidente, hemos de inferir la necesaria existencia de las especies de las sustancias aunque ellas no estén en condiciones de afectar nuestros órganos de recepción sensorial. Bacon no descubre las especies sustanciales, sino que las impone como una demanda de la razón; la existencia de las especies sustanciales es una exigencia que deviene de las demandas metafísicas y de las limitaciones epistemológicas mencionadas.

A diferencia de Lucrecio, quien pensaba que los objetos desprendían desde sus superficies fragmentos que hacían las veces de copias de ellos mismos, Bacon está inclinado a pensar que las especies no preexisten en el agente y no existe el tipo de emisión al que alude Lucrecio. Prueba de ello es que recibimos especies de los ob-

\footnotetext{
${ }_{18}$ Multiplicatione, I, cap. 2, 55-58.

${ }_{19}$ Perspectiva, I, cap. 2, 74-79.
} 
jetos celestes cuando no tendríamos por qué esperar que emitieran fragmentos de sí mismos, dado que ellos son incorruptibles. De hecho las especies no son corporales, pues de ser así tendrían que ocupar un espacio y, por ello, tendrían que desplazar partes del medio receptor para que el lugar vacío pudiese recibir las especies. Como no se percibe en el medio receptor ninguna clase de acomodamiento para facilitar la aceptación de las especies, hemos de concluir que ellas no precisan de un lugar determinado y, por ello, no pueden tenerse como cuerpos..$^{20}$ Tampoco conviene concebir la transmisión al estilo de Aristóteles, quien usaba la figura de la recepción de las formas sensibles en el alma a la manera de un sello que imprime su figura en un bloque de cera. Lo que Aristóteles quiere subrayar, de acuerdo con la lectura que propone Bacon, es que la impresión de las formas sensibles en el alma surge de una alteración que despierta la potencialidad activa de la materia del receptor. Así las cosas, el agente que entra en contacto con el receptor en la periferia, está en condiciones de despertar la potencialidad activa de este último para posibilitar la recepción de las especies del primero. ${ }^{21}$ Aquí surge entonces una dificultad: si una especie de un accidente, que no surge de la nada y tampoco fluye desde el agente por una suerte de emisión, se replica a la manera de un accidente gracias a un ejercicio que permite despertar la potencialidad activa del receptor, bien podemos pensar que la especie así generada es una forma accidental nueva en el receptor: «En consecuencia, dado que el medio es la causa material, en el que y desde cuya potencialidad se genera una especie por el agente y generador, esta especie no puede tener una naturaleza corporal distinta a la del medio». ${ }^{22}$ Así las cosas, ¿por qué hemos de admitir que la forma sustancial del agente debe replicar también una especie sustancial? Quizá no es necesario ese salto que responde a una exigencia metafísica si se admite que la sustancia del receptor es ya el asiento de las especies motivadas por la presencia cercana (contacto) del agente. ${ }^{23}$ Este movimiento, sin embargo, acarrearía una seria dificultad: las especies sensibles (como el color) no darían cuenta de cualidades primarias del agente; no mostrarían un rasgo propio del objeto, sino la manera como el objeto afecta nuestras formas de recepción. El color de una rosa que percibimos ya no podría captarse como la expresión directa de una cualidad de la rosa; sería ahora la expresión de la manera como la rosa nos afecta a nosotros.

\footnotetext{
${ }^{20}$ Multiplicatione, III, cap. 1. Este razonamiento presenta una premisa que se impone como resultado de un razonamiento propter quid, complementada con una premisa recogida a raíz de un razonamiento quia.

${ }^{21}$ A propósito de la potencialidad activa, véase las distinciones trazadas por Aristóteles, Metafísica, Madrid: Editorial Gredos, 1994, IX, caps. 1-5.

${ }^{22}$ Multiplicatione, III, cap. 1, 36-38.

${ }^{23}$ Yael Raizman-Kedar introduce el término Principio de Incorporación para aludir al hecho de que las especies deben ser incorporadas (yo diría asimiladas) en el trasfondo de una clase adecuada de medio. Cfr. Y. Raizman-Kedar, "The Intellect Naturalized: Roger Bacon on the Existence of Corporeal Species within the Intellect", en Early Science and Medicine 14, 2009, p. 142.
} 
El estudio de la multiplicación de las especies en Bacon es un estudio de la propagación de los efectos causales. Este trabajo lleva al filósofo a concluir, en primer lugar, que: «[L]a primera verdad es que la primera parte del recipiente, al ser transformada y poseer efectivamente especies, transforma la segunda parte, la segunda parte transforma a la tercera y asi en adelante». ${ }^{24}$ Así las cosas, una vez actualizada la especie en la primera capa del receptor, se inicia una cadena de multiplicaciones iteradas. Dado que la primera parte del receptor posee ya una especie en todo su vigor, ello la habilita para provocar en la segunda capa una especie similar. Bacon alude a un pasaje de Aristóteles que no especifica con claridad. Puede tratarse del siguiente pasaje del tratado Acerca de los ensueños: «Pues lo que se ha calentado por algo caliente, calienta la parte contigua y eso se va transmitiendo hasta el [final], de forma que también es forzoso que lo mismo ocurra en la percepción, dado que la sensación en acto es un tipo de alteración». ${ }^{25}$ En el marco de este encadenamiento, el agente provoca una alteración en la última capa del recipiente, no porque obre sobre ella directamente, sino porque dispara o detona una reacción en cadena. Un lector contemporáneo podría ver allí la formulación de una propagación ondulatoria: la transferencia de una perturbación en el medio que, sin movilizar un agente material, despierta la potencialidad activa del receptor. No es el agente quien transfiere las especies al receptor, sino quien perturba la primera capa del medio para que despierte su propia potencialidad activa y multiplique, siguiendo la misma dinámica, la producción de semejanzas (especies) en la capa siguiente, y luego en la siguiente y más. La idea del traslado de una perturbación a través de un medio, que no implica que partes del medio acompañen la perturbación, se puede advertir en pasajes como el siguiente: «Y en consecuencia nada se mueve de lugar a lugar; en la misma forma, la sombra no es movida, sino que nuevas sombras son [continuamente] generadas» ${ }^{26}$ En el siglo XX, Wesley Salmon, sin mencionar a Bacon, se ha valido de una idea similar para distinguir entre procesos causales y pseudoprocesos: un proceso causal efectivo arrastra una marca, en tanto que un pseudoproceso no puede hacerlo. Así entonces, una sombra no puede arrastrar consigo una marca. ${ }^{27}$ Cuando, en un día iluminado, un hombre camina, su sombra se desplaza sobre el piso. La sombra se va acomodando (i) a las irregularidades del piso, pero no es capaz de arrastrar consigo fragmentos mismos del lugar. Este desplazamiento de la sombra en el piso ilustra lo que Salmon quiere reconocer como un seudoproceso. No hay en un seudoproceso una transferencia causal efectiva. Cuando hablamos del movimiento de una sombra, no hemos de pensar en un ente corporal que para desplazarse tiene que ir haciéndose a su propio lugar desplazando

\footnotetext{
${ }^{24}$ Multiplicatione, II, cap. 1, 11-13.

${ }_{25}$ Cfr. Aristóteles, Acerca de los ensueños, en ARISTOTELES Tratados breves de historia natural, Madrid: Editorial Gredos, 1987b, II, 459b 3-9.

${ }^{26}$ Multiplicatione, III, cap. 1, 71-73.

${ }^{27}$ Cfr. W. Salmon, Causality and Explanation, New York: Oxford University Press, 1998.
} 
los objetos que le resisten. Para insistir en la semejanza que advertimos con la distinción de Salmon entre proceso causal y peudoproceso veamos el siguiente pasaje completo de Bacon: ${ }^{28}$

«[U]na especie no requiere de un lugar, como sí lo requiere un cuerpo, pero requiere de un soporte, y este soporte no necesita ser numéricamente uno, sino que puede ser constantemente diferente, dado que una especie generada en un lugar del medio puede producir su semejanza en otra parte del medio; y en consecuencia, no hay adquisición de lugar de la misma manera que lo requiere un cuerpo; sino que existe una renovación de especies por generación en varias partes del medio. Pero por el hecho de que exista una diferencia entre esto y la sombra no se sigue que una especie es un cuerpo: dado que una especie tiene una virtud activa por la cual produce su semejanza a lo largo de todos los diámetros en la parte del medio inmediatamente adyacente; mientras que la sombra no es activa, ni es capaz de generar su semejanza, sino que es generada por otro y requiere de esta otra cosa, digamos, del sombrio cuerpo, en adición al medio en el cual llega a su ser. Pero una especie, una vez ha sido multiplicada en el medio, requiere sólo del medio; y por sí misma, gracias a su poder activo, puede producir sus semejanzas»

Bacon concluye también que: «[D]esde un punto singular, ora en la última parte del agente, ora, más propiamente, en la primera parte del recipiente [afectada por ésta última parte del agente], se da una multiplicación virtualmente infinita de especies en forma radiante». ${ }^{29}$ Cada punto de la capa superficial de un agente se convierte en una fuente radiante de especies en todas las direcciones. Esta figura, sin embargo, no debe llevarnos a pensar en una fuente de proyectiles materiales. La presencia del agente basta para disparar en forma radiante un proceso de multiplicación de especies sensibles en todas las direcciones, valiéndose para ello de la potencialidad activa del medio.

De otra parte, «[L]as líneas a lo largo de las cuales ocurre la multiplicación deben ser rectas, hasta donde la naturaleza de la multiplicación lo determine, hasta que ellas encuentren impedimentos que causan reflexión, refracción o sean alteradas a causa de las necesidades del alma». ${ }^{30}$ Bacon se apoya en la tradición (Ptolomeo ${ }^{31}$

\footnotetext{
${ }_{28}$ Multiplicatione, III, cap. 1, 105-122. Bacon usa este argumento para responder cómo puede hablarse del desplazamiento de una especie por un medio cuando se admite que (i) la especie no es un cuerpo, y en consecuencia no se le puede asignar extensión propia, y (ii) el medio no acompaña directamente el desplazamiento de la especie.

${ }^{29}$ Multiplicatione, II, cap. 1, 25-28.

${ }^{30}$ Multiplicatione, II, cap. 1, 61-64. Cuando Bacon menciona las necesidades del alma, se refiere al intrincado recorrido que han de seguir las especies cuando se multiplican a lo largo de los caminos tortuosos definidos por los nervios para llevar la información hasta el cerebro.

${ }_{31}$ Cfr. Ptolomeo (1996), III, § 14. Sin embargo Ptolomeo, en defensa del extramisionismo, habla de la propagación rectilínea desde el ojo hasta el objeto.
} 
y Alhacén ${ }^{32}$ ) y advierte que el ajustarse a la replicación a lo largo de líneas rectas es un deseo de la naturaleza. Este deseo se justifica también acudiendo a las enseñanzas del estagirita: «Aristóteles dice en el libro quinto de la Metafisica que la naturaleza opera en la forma más breve posible, y la línea recta es la más corta de todas». ${ }^{33}$

Bacon advierte cuatro clases de trayectos que unen dos puntos entre los que puede darse la multiplicación de especies. Restringiré el análisis para el caso de la propagación de la luz. En primer lugar, a través de la línea recta que une los dos puntos. A través de este camino se da la multiplicación principal de especies siempre que: (i) el medio en el que se da la multiplicación sea uniforme, (ii) no se encuentre obstáculo alguno a lo largo de dicha recta, (iii) no haya ningún ser animado que se interponga. En segundo lugar, cuando los dos puntos se encuentran en medios diferentes puede ocurrir que: (a) o bien los dos medios coincidan en sus propiedades de transparencia; $; 4$ en este caso la multiplicación principal ocurre a lo largo de la recta que une los dos puntos; (b) o bien, aunque los medios difieran en sus propiedades de transparencia, la recta que une los dos puntos atraviese perpendicularmente la interface entre los dos medios; en este caso la multiplicación principal ocurre también a lo largo de la recta que une los dos puntos; (c) o bien, si los medios difieren en sus propiedades de transparencia y la recta que une los dos puntos atraviesa en forma oblicua la interface entre los medios, la multiplicación principal ha de ocurrir por un camino quebrado (refracción). En tercer lugar, si ocurre que el segundo medio obstaculiza por completo el paso de las especies, éstas no desaparecen sino que regresan al primer medio (reflexión). En cuarto lugar, las especies pueden seguir un camino serpenteante (completamente separado del camino recto) cuando en virtud de las necesidades del alma, ellas tienen que seguir un camino quebrado impuesto por el trayecto de los nervios y las sustancias vivas que los inundan; en otras palabras, dado que los nervios no conducen la información por caminos rectos, sino por caminos intrincados, las especies se deben separar del trayecto recto y ajustarse al que imponen los nervios. Cuando se trata de las especies de las cosas tangibles, éstas se dirigen desde la piel del cuerpo hasta el corazón (el asiento de dichas sensaciones). ${ }^{35}$ Las del gusto también se concentran en un lugar cercano al corazón. ${ }^{36}$

\footnotetext{
${ }^{32}$ Cfr. Alhacén (2001), I, 6.26, 6.27.

${ }_{33}$ Opus majus, Parte IV, dist. 2, cap. 2, p. 131.

${ }^{34}$ La alusión a las propiedades de transparencia es ambigua en la obra de Bacon. En ocasiones el autor identifica dichas propiedades con la densidad del medio.

35 Grosseteste también le asigna un papel protagónico al corazón: «En todos los animales existe un órgano que es el principio originador radical de los sentidos, el movimiento y todos los poderes, naturales, vitales y sensitivos: este es el corazón o algo análogo al corazón» (Grosseteste, Hexaëmeron, Londres: The Oxford University Press, 1982VII, capítulo XIV, 5).

${ }^{36}$ Cfr. Aristóteles, 1987, 439 ; Multiplicatione, II, cap. 2, 98-115; Perspectiva, I, dist. 1, cap. 5, 282-295.
} 
En el caso de la refracción, Bacon advierte en principio que cuando las especies pasan de un medio a otro más denso, éstas toman algún camino intermedio entre la prolongación del trayecto que traían en el primer medio y la perpendicular a la interface en el punto de incidencia (Figura 1, parte izquierda). Si el segundo medio es menos denso que el primero, las especies toman un camino entre la prolongación del trayecto original y la superficie de separación (Figura 1, parte derecha). ${ }^{37}$ Bacon se apoya en Ptolomeo y en Alhacén para sostener que la magnitud de la desviación depende de la diferencia de las densidades de los dos medios y no logra exhibir en forma taxativa el tipo de regularidad que obedece dicha transformación. Según Bruce Eastwood, el primer intento por hallar una ley matemática que estableciera la magnitud del ángulo de refracción, realizado en la Edad Media occidental, fue adelantado por Grosseteste. Con base en argumentos que podríamos caracterizar como a priori, y que a la postre desconocen abrumadora evidencia experimental en contra, Grosseteste, en el ensayo sobre el arco iris (De íride), defiende que el ángulo de refracción (medido desde la perpendicular trazada a la superficie de interface en el punto de incidencia) debe bisecar el ángulo tendido entre dicha perpendicular y la extensión del rayo de incidencia en el segundo medio, que se supone más denso que el primero. ${ }^{38}$ Grosseteste deriva este curioso resultado a partir de la formulación de una analogía entre la refracción y la reflexión y a partir de un principio de economía que parece sugerir que la naturaleza siempre obra por el camino más óptimo posible. Dado el protagonismo de tales principios a priori, Eastwood se anima a concluir: «La asi llamada ley cuantitativa de la refracción [la de Grosseteste] es en consecuencia semicuantitativa, pues está basada sobre principios cualitativos y por esa razón podría mejor llamarse la ley cualitativa de la refracción». ${ }^{39}$

\footnotetext{
${ }^{37}$ Estos dos resultados ya eran bastante conocidos desde la época de Ptolomeo. Véase también (Multiplicatione, V, cap. 2).

${ }^{38}$ Cfr. R. Grosseteste, "On the Rainbow”, en E. GRANT, 1974, p. 390.

${ }^{39}$ Cfr. B. S. Eastwood, "Cuantitative' Law of Refraction: A Chapter in the History of Nonexperimental Science", en Journal of the History of Ideas, Vol. 28, №. 3, 1967, p. 413. En éste artículo Eastwood trata de mediar entre las diferentes traducciones ofrecidas por Crombie y Turbayne. Véase A. C. Crombie, 1953, p. 123.
} 

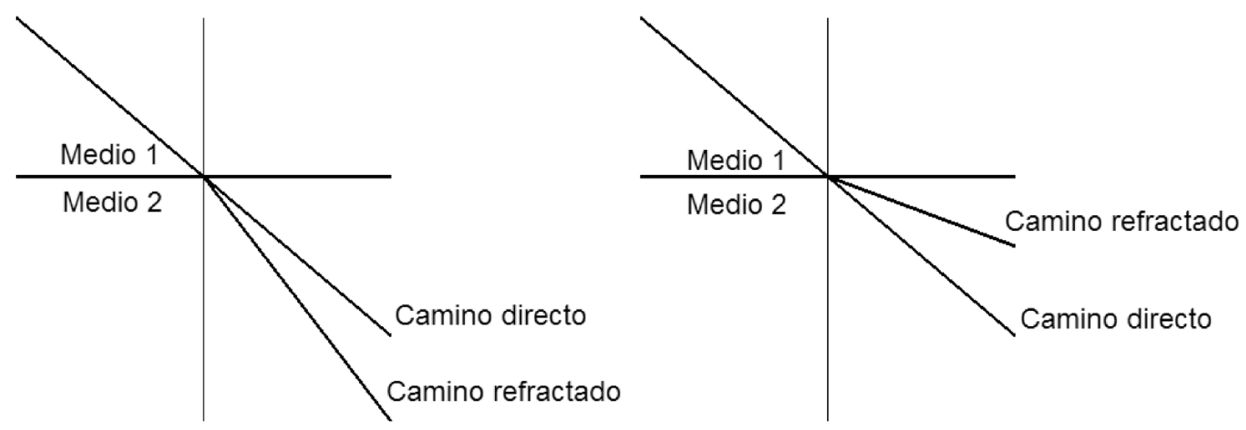

Figura 1

Bacon intenta dar una explicación del mecanismo implícito en la refracción. Dicha explicación vacila entre, por un lado, ofrecer algunas evidencias sensoriales incontestables, $y$, por otro lado, construir un relato plausible. ${ }^{40}$ De cualquier manera, el ejercicio de explicación fracasa porque, en el primer caso, esas evidencias sensoriales tan sólo constatan el fenómeno que se quiere explicar, y, en el segundo caso, los relatos son tan misteriosos como el fenómeno mismo. Veamos cómo procede el intento. Bacon advierte, primero, que una especie que incide perpendicularmente es más fuerte en su intento por penetrar el segundo medio que una que lo hace en forma oblicua. Este hecho lo constatan fenómenos familiares como el que se manifiesta cuando una piedra que desciende perpendicularmente y es desviada de su caída vertical, pierde con ello poder de penetración. La analogía con el caso de la piedra no es del todo conveniente, pues no es la piedra la que inicia un proceso de replicación de especies, sino que es ella misma quien se desplaza abriéndose camino entre el medio que se le interpone. La mayor fortaleza de cualquier intento de penetración perpendicular también es subrayada por Grosseteste: «[U]n rayo incidente en ángulos iguales (esto es, perpendicularmente) conserva un progreso rectilíneo y es el rayo más fuerte». (Grosseteste (1974), p. 387). ${ }^{41}$

Ahora bien, si el segundo medio resiste a tal grado la penetración, que la hace imposible, el objeto que pretende incidir perpendicularmente regresa por el mismo camino, en tanto que el que intenta incidir en forma oblicua es desviado en una dirección simétrica con la original. Este hecho también es constatado con experiencias familiares que sugieren la incontestabilidad del argumento para un lector medie-

\footnotetext{
${ }^{40}$ Multiplicatione, II, cap. 3, 81-168. Aquí se percibe nuevamente la tensión entre una demostración propter quid y una argumentación quia.

${ }^{41}$ Cfr. Grosseteste, 1974, p. 387. Grosseteste también menciona como argumentos: (i) la incidencia perpendicular define el trayecto más corto entre un punto y la recta que sirve de interface entre dos medios; (ii) dado que la perpendicular se define a partir de la igualdad entre un ángulo y su suplemento, de ello se infiere mayor uniformidad y de esta se infiere un mayor poder (Grosseteste, 1974, p. 386).
} 
val. ${ }^{42}$ Las situaciones familiares permiten defender que existe un mayor poder de penetración si la incidencia es perpendicular y ello se manifiesta en la conservación del trayecto directo. ¿Qué ocurre si el segundo medio permite la penetración? No puede esperarse el mismo comportamiento si la especie intenta ingresar perpendicularmente o si lo hace en forma oblicua. Dado que el camino directo es naturalmente más poderoso que el camino quebrado, es de esperar que la continuación directa sea la propia de las especies que inciden perpendicularmente y el camino quebrado el propio de las especies que inciden en forma oblicua. ${ }^{43}$ Bacon retoma la explicación sugerida por Grosseteste: "[U]na línea recta posee igualdad dado que carece de ángulos; pero lo igual es superior a lo desigual [... $]^{44}$ Dado que existe una mayor unidad en la línea recta que en la línea quebrada, como se asevera en el libro $V$ de la Metafísica, en consecuencia la acción a lo largo de una línea recta es más fuerte». ${ }^{45}$ Así entonces, el nuevo medio debe resistir con mayor fuerza a las especies que inciden en forma oblicua. Además, cuanto más oblicua sea la penetración, mayor será la resistencia. Por esta razón, cuando la especie incide en una dirección oblicua: «la virtud natural que genera la especie desea el trayecto más fácil y así lo elige» ${ }^{46} \mathrm{El}$ trayecto más fácil es aquel en el que disminuye la resistencia; esto es, aquel que se encuentra más cerca de la perpendicular. El intento de explicación de Bacon da unos giros que no se pueden justificar con facilidad. En primer lugar, sugiere que la efectividad de la penetración depende del tipo de incidencia de la especie penetrante, pero a continuación advierte que la diferencia reside en la manera como se resiste el medio. ${ }^{47}$ En particular, el medio resiste con mayor fuerza a la penetración oblicua. En la dirección vertical hay una resistencia que, aunque es la menor de todas, ha de producir una disminución en la celeridad. Así las cosas, se supone la existencia de un gradiente de resistencias ajustado al grado de inclinación de la incidencia intentada. La especie que ingresa en forma oblicua será desviada de su trayecto directo, mostrando así que el medio ejerce una mayor resistencia comparada con la que experimenta una especie que ingresa perpendicularmente. Esta especie no toma ahora un trayecto perpendicular porque ese trayecto sólo es propio de las especies que ingresan perpendicularmente; ha de buscar, entonces,

\footnotetext{
${ }^{42}$ Las situaciones familiares son del siguiente talante: si una persona cae verticalmente desde una gran altura puede ver afectada su integridad personal. Si ésta persona cae desde la misma altura pero por un trayecto que se separa drásticamente del trayecto vertical, podría llegar al suelo sin comprometer su integridad personal (Multiplicatione, II, cap. 3, 85-88).

${ }_{43}$ Hay un intento de explicación de esta preferencia en Opus Majus, IV, dist. 3, cap. 1, p. 140. Allí se alude a que la perpendicular define el trayecto más corto entre un punto y un objeto alejado.

${ }^{44}$ Grosseteste cita en su auxilio la Aritmética de Boecio. Este argumento también está presente en la Metafísica de Aristóteles (V, cap. 6, 1016a, 12-13)

${ }^{45}$ Grosseteste (1974), p. 386.

${ }^{46}$ Multiplicatione, II, cap. 3, 139-140.

${ }^{47}$ Bacon ofrece, en el capítulo 1 del libro IV, argumentos que prueban que un medio ofrece resistencia a las especies.
} 
un trayecto intermedio entre el que ofrece una mayor resistencia (a lo largo de la continuación del camino en el primer medio) y el que ofrece la menor resistencia. Ese ejercicio de optimización lleva a la especie a conducirse por un camino intermedio entre el trayecto directo y la perpendicular trazada a la línea de interface. La explicación de Bacon depende de la aceptación del principio de economía que ya hemos citado: «[L]a virtud natural hace que las especies deseen el paso más fácil $y$ lo elijan». No se entiende por qué la especie ha de tomar el camino que le resulte más fácil; y si es así, por qué la especie no toma ahora el trayecto perpendicular a la interface, toda vez que es el camino de menor resistencia. ${ }^{48}$

Grosseteste ofrece un argumento para defender el gradiente de resistencias que menciona Bacon. En la primera parte del argumento se aduce que el poder incidente a lo largo de una línea refractada es mayor al poder incidente a lo largo de una línea reflejada.$^{49}$ Esto se deriva de reconocer que es menor la desviación del camino recto (que es el de mayor poder como se defendió antes) que se consigue con una línea refractada cuando se compara con la desviación lograda en la línea reflejada (que en ocasiones puede alcanzar una magnitud de $180^{\circ}$ ). En ese orden de ideas, es mayor el poder de penetración cuando la especie se pliega a la perpendicular que cuando lo hace a la superficie de separación. Esto se infiere porque en ese caso el trayecto se aleja más de la reflexión.

Si el segundo medio es más sutil, hemos de esperar, de acuerdo a los razonamientos de Bacon, los efectos contrarios. En este segundo caso, aduce Bacon sin ofrecer explicación alguna, que dado que la resistencia en el segundo medio (el más sutil) es de menor intensidad, ya no es imperativo para la especie buscar el camino de menor resistencia:

«Dado que existe una gran resistencia en el primer cuerpo (el más denso) [...], no es necesario para las especies buscar un camino más fácil (esto es, hacia la perpendicular), dado que cualquier camino es más fácil en comparación con la dificultad experimentada en el primer cuerpo. En consecuencia, la especie es capaz de asumir una dirección alejada de la perpendicular, y debe necesariamente elegir dicha dirección, pues en tanto le sea posible actúa de manera uniforme». ${ }^{50}$

Este es un pasaje difícil de seguir. De hecho se habla del desplazamiento de una especie como si se tratara de una unidad que pudiese rastrearse por una extensión que le es propia. En otras palabras, como si se tratara de proyectiles. De otra parte, o bien el principio de mayor economía (aquel que llevaría a la especie a buscar el trayecto más simple en lo que a la resistencia se refiere) no es de estricta obediencia y hay, en consecuencia, circunstancias que ameritan su desatención; o bien,

${ }^{48}$ Grosseteste cita un principio similar (Grosseteste, 1974, p. 386).

49 Bacon retoma este argumento en Multiplicatione, V, cap. 2, 61-64.

${ }^{50}$ Multiplicatione, II, cap. 3, 146-155. 
debe existir otra regla que prevalece sobre el principio. La primera alternativa debe llevarnos a reconocer que hay principios diferentes para explicar el paso desde un medio menos denso a uno más denso, comparado con el paso desde uno de mayor densidad a uno de menor. La segunda alternativa privilegia la uniformidad explicativa, pero debe conducirnos a reemplazar la explicación sugerida en el primer caso. En mi opinión Bacon adopta la segunda alternativa. En aras de salvar la unidad de la explicación, se hace necesario revisar el intento formulado para dar cuenta del paso del medio de menor densidad al medio de mayor densidad. Las especies no buscan siempre el camino de mayor economía, sino el camino que maximiza la uniformidad. ¿A qué se refiere, pues, Bacon con la uniformidad aludida? Dado que en el primer medio hay más resistencia, habría que buscar ahora (en el segundo medio) el camino de mayor resistencia para conservar la uniformidad. Por esa razón la especie ya no busca acercarse a la perpendicular, sino alejarse de ella. Así entonces, si el segundo medio es más denso, la especie experimenta una mayor resistencia que la que ofrece el primer medio; en virtud del principio, debe buscar caminos que ofrezcan menor resistencia y ellos existen plegándose más hacia la dirección perpendicular a la interface. Si el segundo medio es menos denso, se experimenta ahora menor resistencia y, en virtud del principio, la especie debe buscar recorridos que ofrezcan mayor resistencia; esto es, caminos más alejados de la perpendicular a la interface. Citemos el desarrollo de la explicación de Bacon y tratemos de notar que hay ahora un ejercicio en el que se replantea la primera explicación sugerida:

En conformidad, dado que en el primer cuerpo esta [la especie] tenía gran dificultad o [únicamente] moderada facilidad de tránsito, por efectos de la uniformidad (la cual se mantiene tanto como sea posible), ella no puede elegir el superior de los [dos] contrarios, de acuerdo con el cual se desviaría hacia el camino más fácil (esto es, hacia la perpendicular); sino que hasta un cierto grado, tanto como ella pueda y deba, mantendrá [su] dificultad o disminuirá la facilidad del tránsito; y esto ocurre tan pronto como la especie se desvía del camino directo en la dirección que se aleja de la perpendicular [...] En forma similar, cuando una especie pasa desde un medio más sutil a uno más compacto, mantiene su facilidad de tránsito en la segunda sustancia, así que su paso a través de las dos sustancias es, tanto como le resulta posible, proporcional y uniforme; al mismo tiempo, la mayor compactación de la segunda sustancia excita el poder de generación de especies, de tal manera que las desvía hacia la dirección del tránsito más fácil. ${ }^{51}$

La corrección se formula, sin embargo, con cláusulas ceteris paribus añadidas a la presentación. En la naturaleza se conserva cierto principio de uniformidad tanto como sea posible. Cuando el tránsito avanza desde un medio menos denso a uno más denso, la trayectoria impuesta por la exigencia de la uniformidad coincide

${ }^{51}$ Multiplicatione, II, cap. 3, 155-168. 
con la trayectoria impuesta por el principio de economía. No ocurre así cuando el tránsito avanza desde un medio de mayor densidad a uno de menor densidad. El principio de uniformidad podría enunciarse con cierta similitud o familiaridad a un principio de inercia: las especies se desplazarán por trayectos que procuran conservar, siempre que nada lo impida, las mismas condiciones de resistencia que le anteceden. Dado el gradiente de resistencias que advertimos con anterioridad, cuando la resistencia global del nuevo medio aumenta, las especies se plegarán a la dirección en donde la resistencia parece disminuir, es decir hacia la perpendicular. Cuando dicha resistencia global disminuye, las especies desvían su trayecto original hacia las direcciones que ofrecen mayor resistencia, es decir lejos de la perpendicular.

Cuando Ptolomeo se ocupó de la refracción trató, en primera instancia, de hallar una regla cuantitativa y para ello adelantó varios experimentos que no condujeron a resultados sobresalientes. Los textos recuperados no dejan ver que Ptolomeo tuviese en sus manos una explicación cualitativa. Sin embargo, en un breve pasaje Ptolomeo advierte que la búsqueda de una explicación cualitativa debe mostrar que tal comportamiento de la luz debe explicarse en virtud «del curso de la naturaleza por conservar el ejercicio del poder». ${ }^{52}$ La Figura 2 ilustra el tipo de razonamiento de Bacon. En el medio 1 se da un proceso de multiplicación de especies cuyo poder de multiplicación se puede representar por un vector. Dado que el medio 2 difiere en sus propiedades de transparencia con respecto al medio 1, podemos representar por medio de vectores la variación en el poder de multiplicación si asumimos que la multiplicación principal ocurriera en las direcciones trazadas en forma discontinua. La multiplicación principal ha de ocurrir en aquella dirección que reproduce la magnitud del vector del medio inicial. Cuando el medio 2 es menos denso, ello ocurre alejándose de la normal (como ilustra el lado izquierdo de la figura), cuando el medio 2 es más denso, ello ocurre acercándose a la normal (como ilustra el lado derecho de la figura).

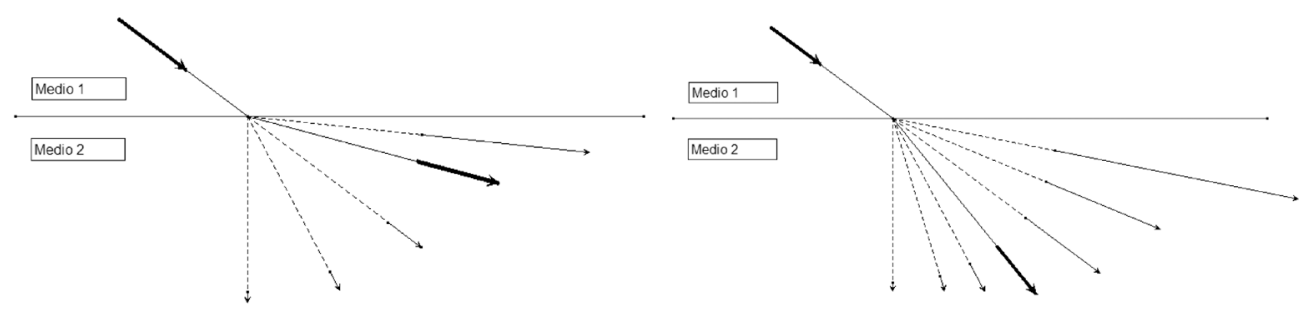

FIGURA 2

La nueva propuesta de Bacon tampoco resulta del todo satisfactoria. Esta propuesta fracasa cuando tenemos que explicar el comportamiento de las especies que

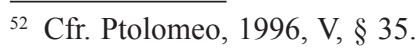


atraviesan desde un medio a otro en forma perpendicular. La evidencia experimental sugiere que las especies no cambian de dirección y este hecho lleva a Bacon (y a Grosseteste) a argüir que en esa dirección se ejerce la menor resistencia. Sin embargo, la ley propuesta exigiría que la especie cambiara de dirección para ajustarse a una nueva dirección en donde se conserve el poder de multiplicación que se tenía en el primer medio.

El patrón de multiplicación de especies de Bacon es interesante porque parece sugerir las bases de un tipo de transporte ondulatorio a través de un medio. Sin embargo, el modelo contrasta con la formulación de ejemplos o analogías propias del movimiento de proyectiles. Bacon habla de bloques de piedra penetrando en un medio resistente, hachas que penetran la madera. ${ }^{53} \mathrm{La}$ descripción de Bacon es cualitativa, toda vez que no cuenta con una ley cuantitativa precisa. Los intentos de Ptolomeo no llegaron a ser lo suficientemente sugerentes como para pensar que se tenía una ley precisa y los intentos de Grosseteste entraban en contradicción con la evidencia experimental más simple. La aparición de dicha ley aún debía esperar algunos siglos de exploración. Johannes Kepler a comienzos del siglo XVII hizo esfuerzos matemáticos sorprendentes para recoger los datos de refracción del paso de la luz del aire al agua, datos recogidos en la obra de Witelo a partir de la información que reposaba en la obra de Alhacén, sin lograr advertir con claridad una ley satisfactoria. ${ }^{54}$ La ley que a la postre resultó exitosa llegó a tener la forma de una razón constante entre el seno del ángulo de incidencia y el seno del ángulo de refracción. ${ }^{55}$ Esto es: $\frac{\operatorname{sen}(i)}{\operatorname{sen}(r)}=c$ ( $c$ : constante). Ahora bien, aún contando con una ley empíricamente adecuada, el modelo para la replicación de la luz seguía siendo un misterio difícil de desentrañar. En caso de adoptar modelos mecanicistas, similares

\footnotetext{
${ }_{53}$ Multiplicatione, II, cap. 3, 81-98.

${ }^{54}$ Véase KEPLER, J. Optics: Paralipomena to Witelo \& Optical Part of Astronomy. Santa Fe: Green Lion Press, 2000, Capítulo IV.

${ }^{55}$ La primacía de la ley se debate entre Thomas Hariot y Willebrord Snellius. La ley también suele atribuirse a Descartes. Roshdi Rashed ha propuesto también que hay claros antecedentes de la formulación de una ley en tal dirección en los trabajos de Ibn Sahl, un matemático árabe del siglo $\mathrm{X}$ anterior a Alhacén. Rashed también sugiere que Alhacén tenía información de los trabajos de Ibn Sahl. Aunque la hipótesis es interesante y tiene una fuerza argumentativa poderosa, conviene aclarar que el trabajo de Ibn Sahl no hacía parte de un programa de investigación que pretendiera ofrecer una explicación completa a la refracción. Sus escritos se circunscribían al ámbito de la solución de un problema matemático asociado con la forma que había que dar a las superficies reflectantes o a las superficies de las interfaces de medios distintos para conseguir concentrar los rayos de luz que provienen de una fuente, bien sea cercana a un espejo (caso en el cual habría que recurrir a superficies elípticas), bien sea lejana a un espejo (caso en el cual los rayos inciden en forma paralela y se debe recurrir a una superficie parabólica), o bien sea lejana a una lente (caso en el cual habría que pensar en una superficie hiperbólica). Véase R. Rashed, "A pioneer in Anaclastics: Ibn Sahl on Burning Mirrors and Lenses”, en Isis, Vol. 81, No. 3, 1990, pp. 464-491.
} 
al sugerido por Descartes, por ejemplo, la ley tiene la forma: $\frac{\operatorname{sen}(i)}{\operatorname{sen}(r)}=\frac{v_{2}}{v_{1}}\left(\operatorname{siendo} v_{2}\right.$ la velocidad en el segundo medio y $v_{l}$ la velocidad en el primero). Cuando la luz pasa del aire al agua se puede establecer experimentalmente que $\operatorname{sen}(i)>\operatorname{sen}(r)$; de la ley de Descartes se desprende que $v_{2}>v_{1}$ (la velocidad de la luz en el agua debe ser superior a la velocidad de la luz en el aire, por lo tanto es mayor la resistencia que ofrece el aire). ${ }^{56}$ En caso de adoptar un modelo ondulatorio, similar al de $\mathrm{Hu}-$ ygens, por ejemplo, la ley resulta ser: $\frac{\operatorname{sen}(i)}{\operatorname{sen}(r)}=\frac{v_{1}}{v_{2}} \cdot{ }^{57}$ Así, cuando la luz pasa del aire al agua, pasa a un medio en donde se propaga con una velocidad menor, contrario a la expectativa mecanicista. Dado que para ese entonces no había métodos confiables para medir la velocidad de la luz, los dos modelos podían contar con el beneficio de la plausibilidad.

\section{La Perspectiva communis de John Pecham}

John Pecham nació cerca al año 1230 muy posiblemente en la villa de Patcham. Es absolutamente indudable que el espíritu de Bacon corre por las páginas de la obra de Pecham. Esto se puede defender sin acudir a alguna referencia explícita del nombre de Bacon en la obra de Pecham; de hecho no existe referencia alguna. La influencia se advierte en los problemas tratados, en las categorías empleadas (especies, pirámides), en los argumentos, en el deseo de incorporar el lenguaje de las matemáticas como el instrumento adecuado para plantear y enfrentar los problemas. Las que no resultan del todo claras son las circunstancias en las que pudo ejercerse la influencia. Bacon y Pecham pudieron tener algún contacto en 1260 cuando ambos coincidieron en las residencias de los franciscanos en Paris en la época en la que Bacon ya había reorientado sus intereses científicos en favor de alguna forma de matematización. Crombie sostiene, sin que sus argumentos sean concluyentes, que la influencia de Bacon sobre Pecham debió darse con la intermediación de Witelo. ${ }^{58}$

El trabajo más influyente de Pecham, posiblemente compuesto entre 1269 y 1275, se conoce hoy bajo el título de Perspectiva communis. Este título no fue su-

\footnotetext{
${ }_{56}$ Cfr. Descartes, 1988, La Dioptrique, Discurso segundo (De la Refracción), pp. 93-106. La estrategia básica de Descartes consiste en descomponer la velocidad de la luz en una componente paralela y otra perpendicular a la línea de interface. Así, el medio resiste en la dirección perpendicular y asegura la conservación de la componente paralela. Lindberg cree que Descartes pudo haberse inspirado en algunos pasajes del Libro VII de De Aspectibus de Alhacén en donde se recomienda una forma similar de descomposición (D. C. Lindberg 1968, p. 35).

${ }^{57}$ Fue Huygens quien en 1703 dio a conocer los resultados de los trabajos de Snell.

${ }^{58}$ Cfr. A. C. Crombie, 1953, p. 165.
} 
gerido por su autor; sino que parece haberse impuesto en algún momento del siglo XIV y sólo llegó a estandarizarse en el siglo XVI, gracias a la aparición de las ediciones impresas. ${ }^{59} \mathrm{El}$ complemento que acompaña al título sin duda alude al hecho de que el texto llegó a ser una de las puertas de entraba al estudio de los temas propios de la perspectiva (o de la óptica) ${ }^{60}$ Hay muchas evidencias que muestran que el libro de Pecham servía como texto introductorio en las principales universidades de Europa (Viena, Praga, Paris, Leipzig, Alcalá, Salamanca, Würzburg).

Cuando Pecham quiere explicarle al lector por qué la luz cambia de dirección cuando cambia de medio es claro que copia los modelos de argumentación de Bacon y Grosseteste. Sin embargo, no ahorra reparos para protestar contra el finalismo que se insinúa en la explicación de Bacon. Voy a presentar el modelo de argumentación de Pecham y me voy a tomar la libertad de enumerar las partes que creo vislumbrar en el argumento. ${ }^{61}$ (i) «La causa universal de la refracción es la variación en la transparencia [...] En consecuencia, dado que existe una diferencia en la facilidad con la cual un medio puede ser atravesado, se sigue necesariamente que la dirección del rayo en el segundo medio [...] guarda una proporción con la dirección en el primer medio semejante a la proporción que guarda la resistencia en el segundo medio con la resistencia en el primero». Pecham intuye, pues, una especie de ley cuantitativa que debería expresar la identidad entre la relación de las direcciones de los rayos de luz (expresión de los efectos) y la relación entre los grados de transparencia (expresión de las causas), lo que quiera que ello signifique. En otras palabras, Pecham trata de dar una formulación cuantitativa al principio de uniformidad sugerido en la obra de Bacon. No hay, sin embargo, un enunciado preciso de la relación cuantitativa que debe guardarse. (ii) «El paso a un nuevo medio es el más fuerte cuando los rayos entran o emergen perpendicularmente y el paso a través de un trayecto no-perpendicular es tanto más débil cuanto más alejado se está de la perpendicular y más fuerte si se aproxima a ella». Este principio resume la insistencia de Grosseteste y de Bacon para sublimar la propagación rectilínea. En efecto, es más fuerte la propagación que implica una multiplicación rectilínea. ${ }^{62} \mathrm{Si}$ las especies ingresan a un segundo medio en una dirección perpen-

\footnotetext{
${ }^{59}$ La obra fue impresa por primera vez en 1483.

${ }^{60}$ Una de las ediciones impresas lleva por título: Perspettiva Joannis Pisani... vulgo communis appellata... Leipzig, 1504.

${ }^{61}$ Pecham I, 15. Para citar a Pecham usaré la edición preparada por Lindberg: LINDBERG, D. C.. John Pecham and the Science of Optics, traducción y edición crítica del Perspectiva Communis de John Pecham. Madison: The University of Wisconsin Press, 1970.

${ }^{62}$ A propósito de los argumentos expuestos por Pecham, véase Pecham, II, 3. Pecham, por ejemplo, pretende derivar la ley de la reflexión que establece que el rayo incidente, la normal y el rayo reflejado se encuentran en el mismo plano a partir del hecho de que los rayos se ajustan al desplazamiento rectilíneo. Si un rayo fuera obligado a desviarse del plano mencionado, se desviaría doblemente del camino rectilíneo: primero, en el quiebre que implica la refracción, y, segundo, en el quiebre adicional que implicaría cambiar de plano. Cfr.Pecham, II, 6 .
} 
dicular a la superficie de separación de los dos medios, es por todos reconocidos que no hay allí desviación alguna del trayecto rectilíneo. Esto ha llevado a suponer que en la dirección perpendicular a la superficie de separación entre dos medios se agencia una mayor transparencia. En resumen, si dos medios difieren en grados de transparencia, hemos de admitir cierto gradiente de resistencias que operan de tal forma que existe menor resistencia a lo largo de la perpendicular y una resistencia cada vez mayor a medida que nos alejamos de la perpendicular. La resistencia no depende, pues, solo de la naturaleza del medio; depende también de la dirección con la que el rayo pretende ingresar al medio. Tanto (i) como (ii) sugieren que son dos las variables a tener en cuenta a la hora de anticipar el tipo de refracción esperada: «[H]ay dos causas de la refracción, una de parte del rayo - a saber, su debilidad a causa de la inclinación- y la otra de parte del medio - esto es, la variación en la transparencia $\rightarrow \gg{ }^{63}$ (iii) «Por lo tanto un rayo que encuentra un medio más denso y más resistente debe asumir una posición más fuerte y cercana al trayecto directo». El rayo no puede seguir el trayecto directo, pues las circunstancias exigen que un cambio en la transparencia se exprese a través de un cambio en la dirección de propagación. Que el rayo cambie de dirección se infiere del cambio en la transparencia de los medios (el poder de multiplicación) y del principio (ii) que en general afirma que un cambio en el poder de multiplicación debe hacerse evidente a través de un cambio en la dirección. Pero, por lo pronto, no hay nada que nos obligue a concluir que el rayo debe asumir la posición más fuerte. El investigador sabe, en virtud de la evidencia empírica más elemental, que cuando el nuevo medio es más denso, el rayo se pliega hacia la normal. También cuenta con la posibilidad de que se pueda enunciar una ley cuantitativa que relacione, por un lado, direcciones en los dos medios con, por otro lado, transparencias de los medios. Sin embargo, no está en condiciones de sugerir dicha ley y ni siquiera de proponer una alternativa a la manera de hipótesis de trabajo. Por lo tanto, nada le autoriza a concluir que el nuevo rayo ha de plegarse a la dirección que implique un mayor poder. (iv) «En consecuencia, para que el paso a través del segundo medio sea conmensurable con el paso a través del primero, el rayo [refractado] se desvía hacia la perpendicular levantada en el punto de incidencia en el segundo medio». Pecham quisiera inferir, a partir de los elementos anteriores, que si la facilidad para multiplicarse en el segundo medio (transparencia) es menor y la proporción entre las transparencias debe ser comparable con la proporción entre las direcciones, debe esperarse que las especies en el segundo medio se acerquen a la dirección perpendicular. Sin embargo, la inferencia no está autorizada mientras no se formule de manera explícita el tipo de relación cuantitativa entre las direcciones y los grados de transparencia. Por ejemplo, si la pretendida relación establece que el ángulo en el primer medio ${ }^{64}$ es al ángulo en el

${ }_{63}$ Cfr. Pecham III, 3.

${ }^{64}$ Medido con respecto a la perpendicular. 
segundo como la resistencia en el primero es a la resistencia en el segundo, debíamos esperar que si la resistencia en el segundo medio es mayor, mayor tendría que ser el ángulo en el segundo medio y, en consecuencia, el rayo tendría que alejarse de la perpendicular. En caso de que la pretendida relación compare la proporción entre los ángulos con la proporción entre las transparencias (imaginando que se trata del inverso de las resistencias), podría esperarse el resultado contrario en las mismas condiciones previas. ${ }^{65}$ En el conflicto comentado se expresa la tensión que vive un investigador cuando reconoce de antemano a dónde debe llegar, pero ignora por completo el camino que le conduce a la meta. Apenas puede divisar una vaga recomendación. Mientras no contemos con una relación cuantitativa explícita, así sea a la manera de hipótesis de trabajo, todos nuestros movimientos conducen a una explicación frustrada.

Esta explicación guarda claras similitudes con la propuesta ensayada por Bacon. Sin embargo, ahora Pecham descarga su reserva crítica: «No debe pensarse que el rayo se desvía hacia la posición más fuerte como si lo hiciera por elección, sino más bien que el paso desde el primer medio obliga a un paso proporcional al segundo». No se trata, entonces, de una suerte de elección de las especies motivada por el deseo de optimizar, por ejemplo, el esfuerzo realizado. En esto es justa la llamada de atención de Pecham. Se trata, más bien, de postular la invariancia de alguna relación matemática de tal manera que, entre las múltiples posibilidades de desviación, se actualiza aquella que conserva la proporción entre grados de transparencia (lo que quiera que ello signifique) y entre trayectorias seguidas (medidas contra la perpendicular entre los dos medios). El imperativo de una ley matemática para dar cuenta de la refracción es, entonces, más fuerte en Pecham que en Bacon. Sin embargo, Pecham no tiene una ley para ofrecer como alternativa; tan solo enuncia su posibilidad. La llamada de atención de Pecham en relación con el finalismo que se insinúa en el bosquejo explicativo de Bacon es atractiva para un lector moderno. Un lector que ha aprendido a ser cauto y escéptico en relación con las explicaciones finalistas y está dispuesto a ser condescendiente con modelos de explicación que pretenden subsumir casos particulares a leyes universales que contienen elementos cuantitativos. Pero un lector medieval puede llegar a sentirse más a gusto con explicaciones finalistas. En ese orden de ideas, si bien la reserva por involucrar elementos finalistas y la invitación a considerar la explicación como el ejercicio que subsume el explicandum a un explanans que contiene leyes cuantitativas, puede resultar atractivo para un lector moderno, el hecho de que la pretendida ley cuantitativa no se enuncie con claridad y genere la impresión de

${ }^{65}$ La primera alternativa se puede formalizar así: $\frac{i}{r}=\frac{R_{1}}{R_{2}}$; por lo tanto: $\left(R_{1}>R_{2}\right) \supset(i>r)$. La segunda alternativa se puede formular así: $\frac{i}{r}=\frac{T_{1}}{T_{2}}=\frac{R_{2}}{R_{1}}$, siempre que $\left(T_{1}=\frac{1}{R_{1}} ; T_{2}=\frac{1}{R_{2}}\right) ;$ por lo tanto: $\left(R_{1}>R_{2}\right) \supset(i>r)$. 
ofrecer una explicación frustrada, puede llevar al lector medieval a simpatizar, con mayor fuerza y sobrada razón, con la explicación finalista de Bacon. La explicación de Bacon, aunque puede parecernos insatisfactoria, no resulta ser propiamente una explicación frustrada.

\section{La Perspectiva de Witelo}

La obra que con mayor fuerza cumplió la tarea de divulgar el espíritu de la nueva perspectiva en occidente fue, sin duda, la obra de Witelo. Witelo nació en Polonia en algún año entre 1220 y 1225 . Witelo recogió todos sus estudios de óptica en un extenso tratado con el título de Perspectiva. ${ }^{66}$ La Perspectiva de Witelo recoge muy pocos resultados originales. Dicha obra presenta, más bien, una interesante síntesis de los estudios más valiosos dedicados a la perspectiva; estudios a los que, por este medio, pudieron tener acceso los investigadores de los siglos por venir. Fue principalmente a través de este vehículo que se pudieron extender los aportes de Alhacén, Grosseteste y Bacon. ${ }^{67}$ Entre los manuscritos y primeras ediciones de la obra de Witelo sobresale la edición preparada por Friedrich Risner (1533-1580) en el año de $1572 .{ }^{68}$

Dado que no hay aportes originales en el tratado de Witelo, su importancia vital reside en un ámbito diferente a la creatividad. El mayor aporte tiene que ver con aspectos didácticos que hicieron más expedito el contacto de los nuevos investigadores con las fuentes clásicas. Witelo presenta una síntesis, recogida de una manera sistemática en un aparato que parece ofrecer una estructura sólida. El autor quiere imitar el estilo de presentación euclidiana: introduce algunas definiciones, formula algunos postulados y desarrolla un cuerpo extenso de demostraciones. ¿En qué medida el autor respeta la estructura euclidiana? es algo que debe juzgar el lector. La pretendida impronta euclidiana ha llevado a Mark Smith a sostener que:

\footnotetext{
${ }^{66}$ Las referencias al tratado de Witelo se harán mencionando en primer lugar el libro (números romanos) seguido del ordinal correspondiente a la proposición (números arábigos). Usaremos las ediciones de UNGURU, S. Witelonis perspectivae liber primus. Book I of Witelo's Perspectiva. Wroclaw: Studia Copernicana XV, The Polish Academy of Science Press, 1977. UNGURU, Sabetai. Witelonis perspectivae liber secundus et liber tertius. Books II and IIII of Witelo's Perspectiva. Wroclaw: Studia Copernicana XXVIII, The Polish Academy of Science Press, 1991. SMITH, A. M. Witelonis perspectivae liber quintus. Book V of Witelo's Perspectiva. Wroclaw: Studia Copernicana XXIII, The Polish Academy of Science Press, 1983.

${ }^{67}$ Las probabilidades de algún tipo de intercambio personal entre Bacon y Witelo son definitivamente muy bajas. Cfr. D. C. Lindberg, "Lines of Influence in Thirteenth-Century Optics: Bacon, Witelo, and Pecham”, en Speculum, Vol. 46, No. 1, 1971, p. 73.

${ }^{68}$ Obra reimpresa en 1972 con la colaboración de David Lindberg.
} 
Witelo en muchas formas hizo por la ciencia de la perspectiva lo que Euclides habia hecho por el estudio de la geometría plana [...] Evaluar otros trabajos, seleccionarlos cuidadosamente, en algunas ocasiones podar, otras veces elaborar y sobre esta base compilar una suma de todo ello, Witelo codificó el estudio de la óptica como nadie lo hizo antes de él. Su originalidad, como la de Euclides, reside más en la habilidad para reunir y sintetizar que en la habilidad para crear. ${ }^{69}$

La estrecha comparación que pretende Smith resulta en varios aspectos desproporcionada. Es cierto que tanto Euclides como Witelo sintetizaron el trabajo de matemáticos y filósofos que les antecedieron; sin embargo, el número de aportes originales de Euclides sobrepasa con creces los escasos aportes originales de Witelo. De otra parte, y esto es quizá lo más importante, la organización dada por Euclides al conocimiento geométrico previo aporta ya un inigualable valor agregado. En general, Euclides respeta el orden de jerarquías entre las definiciones, los axiomas y las proposiciones. Esto garantiza que el régimen de demostraciones se vaya anclando en un edificio en el que los pisos superiores se apoyan efectivamente sobre los cimientos que proveen los pisos inferiores. Esta sistematicidad le permite al lector contemplar de manera articulada el trabajo de los matemáticos griegos en general. No hay en la obra de Witelo esos niveles de organización jerárquica en su estructura y por eso su propuesta de sistematización de la perspectiva no alcanza el valor agregado que sí le impone Euclides a la geometría.

Cuando Witelo se ocupa de la refracción no sólo intenta dar con una explicación cualitativa, sino que ofrece, además, una argumentación instrumental para darle al lector más evidencias que lo lleven a aceptar que cuando la luz pasa de un medio a otro más denso debe refractarse acercándose a la normal. Él utiliza un dispositivo experimental sugerido por Alhacén y, en el libro X, provee información cuantitativa medianamente fiable cuando la luz pasa del aire al agua. Witelo también menciona, en dicho libro, haberse ocupado del paso de la luz del agua al aire y presenta una tabla de datos que no sólo no es fiable, sino que presenta datos que no podría haber tomado de ninguna manera. Witelo no advierte que, en este caso, existe un umbral para los ángulos de incidencia a partir del cual no se produce refracción alguna. Cuando la luz pretende incidir con ángulos superiores a dicho umbral, ella se refleja en su totalidad. ${ }^{70}$ Crombie ha mostrado cuidadosamente los errores en los que cae Witelo cuando pretende ocuparse del paso del agua al aire. A juicio de Crombie,

\footnotetext{
${ }^{69}$ M. Smith, 1983, p. 66.

70 Theodorico de Friburgo (1250-1310) fue el primero en ocuparse de la importancia de la determinación de dicho umbral. Este hecho fue central para advertir que el arco iris habría de explicarse admitiendo primero una refracción en las gotas de agua suspendidas, seguida de una reflexión dada en virtud de la superación del ángulo crítico cuando la luz trata de pasar del agua al aire nuevamente. Este es el camino adoptado por Theodorico. Cfr. E. Grant, 1974, pp. 435-441.
} 
Witelo pretende aplicar equivocadamente una ley de reciprocidad insinuada en la obra de Ptolomeo. ${ }^{71}$

Después de presentar evidencias instrumentales, Witelo asume la empresa de ofrecer una "demostración natural". Voy a examinar con cuidado la propuesta que Witelo expone en la proposición 47 del libro II. Enumeraré los pasos que advierto en dicha argumentación. (i) «En verdad, todos los movimientos naturales que ocurren a lo largo de líneas perpendiculares son más fuertes dado que ellos son ayudados por el poder celestial universal, el cual, ajustándose a la línea más corta, influye sobre cada cuerpo que yace debajo». Aunque Witelo no aclara con respecto a qué deben ser perpendiculares las líneas que menciona, del contexto se infiere claramente que él tiene en mente líneas que se dirigen verticalmente al centro del universo. (ii) Witelo prosigue así:

«Dado que la densidad de cualquier cuerpo impide el paso de la luz, es necesario imaginar la luz como si fuera repelida en su paso gracias a la resistencia del cuerpo denso, y [sería] más repelida aún por la resistencia de un cuerpo más denso. Y entendemos, por esta resistencia de la cualidad pasiva (que es la densidad) sobre una cualidad activa (que es la luz), un cierto modo de movimiento de la luz a través del médium de los cuerpos resistentes, los cuales son más o menos susceptibles a la impresión de la luz; esto no sugiere que hubiese algún movimiento en el desplazamiento local de la luz misma (como es evidente a partir del teorema 2 del presente libro), ${ }^{72}$ sino que en el mismo instante la luz se restringe o se difunde ella misma más, de acuerdo a la diversidad del medio».

No hay duda que Witelo se encuentra en conflicto con el enunciado de la proposición 2. La mayor resistencia debe manifestarse a través de una disminución en la velocidad de dispersión. Pero tal disminución no puede darse si se asume previamente que el despliegue de la luz debe ocurrir de manera instantánea. (iii) «En consecuencia, cuando la luz pasa oblicuamente a través de un cuerpo transparente y encuentra un cuerpo transparente más denso, el último obstaculiza la luz más vigorosamente que el primer cuerpo más rarificado». Dicha obstaculización se manifiesta de la siguiente manera: (iv) «[S]i el rayo de luz incide oblicuamente, no será capaz de continuar por el trayecto directo a causa de la debilidad del movimiento a lo largo de líneas oblicuas; en consecuencia, se desvía hacia una dirección en la cual el tránsito resulte más fácil que en la dirección original». Witelo está siguiendo aquí las huellas del primer intento de solución sugerido por Bacon. Ya están dados, pues, los elementos para identificar el trayecto más simple: (v) «Pero el movimiento más fácil y el que resulta más auxiliado por el poder ce-

${ }_{71}$ Cfr. A. C. Crombie, 1953, p. 225.

${ }_{72}$ Este teorema establece que si la luz no sufre impedimento alguno, ella se expande de manera instantánea. 
lestial ocurre a lo largo de la perpendicular, y aquel que transcurre más cerca de la perpendicular tendrá un tránsito más fácil que aquel que resulte más alejado de la perpendicular». Witelo sugiere, entonces, que los tránsitos más cercanos a la perpendicular resultan más expeditos toda vez que dichos trayectos son auxiliados más efectivamente por los poderes celestiales. La explicación de Witelo supone como trasfondo que la superficie de separación entre los dos medios es perpendicular a las rectas que trazadas verticalmente convergen en el centro del universo. Sólo así se puede esperar el auxilio del poder celestial. Si un rayo de luz que parte de $A$ (Figura 3) y que viaja en el aire incide en el agua precisamente en el punto $B$, no puede continuar en el trayecto recto, sino que debe ser desviado en la dirección que le resulta más fácil. Esta dirección es precisamente una que se acerca a la perpendicular porque así resulta auxiliada por los poderes celestiales que obran radialmente hacia el centro del universo. Por eso toma ahora un trayecto similar a $B C$. La explicación de Witelo no puede extenderse a tránsitos del aire al vidrio, a pesar de que el vidrio sea más denso, cuando la superficie de separación entre los dos no es perpendicular a las líneas radiales que convergen en el centro del universo; cuando el vidrio, por ejemplo, reposa sobre una mesa horizontal y el rayo de luz, aunque incide oblicuamente, lo hace a lo largo del plano que define la superficie de la mesa.

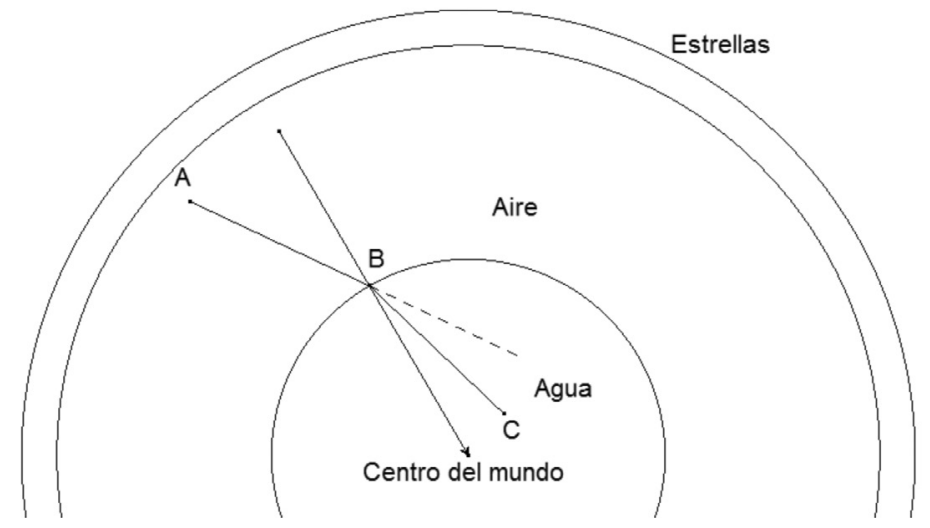

Figura 3

\section{Epílogo}

Las tres explicaciones comentadas ilustran la exigente demanda que existía entre los estudiosos del siglo XIII por encontrar una explicación cualitativa de los fenómenos de refracción. Existe ya una clara conciencia de la necesidad de articular una regla cuantitativa con una explicación cualitativa convincente. Sin embargo, la ausencia de una ley cuantitativa deja abierto un espectro muy amplio de especulaciones cualitativas pues lo único que hay que explicar es por qué, al pasar de un 
medio de menor a uno de mayor densidad, la luz se pliega a la normal, sin atender qué tanto debe plegarse a la misma. Las explicaciones aquí revisadas se pliegan a la metafísica de la multiplicación de efectos causales resumida en la obra de Bacon. El filósofo británico desarrolló la intuición neoplatónica básica, tomada de Grosseteste, según la cual los objetos procuran imitar la dinámica creadora que permite desplegar copias de lo uno para producir lo múltiple. En ese orden de ideas, siempre que un objeto $A$ actúa causalmente sobre otro objeto $B$, está con ello tratando de inducir a $B$ a aceptar una copia de $A$. Este proceso se inicia en las capas externas de $B$, allí donde estas capas están en contacto con la superficie de $A$, y se empieza a replicar capa por capa hacia el interior del medio $B$. Este modelo de multiplicación es el que ha de permitir explicar el fenómeno de radiación luminosa. Es más, la radiación luminosa en capas esféricas a partir de una fuente de luz puntual ofreció el modelo básico para desarrollar las ideas neoplatónicas.

Después de contar con una idea básica acerca de la propagación esférica de la luz, que exigía también un desplazamiento rectilíneo de sus efectos, se hacía necesario explicar la razón por la cual dicha multiplicación cambia de dirección principal cuando la luz pasa de un medio a otro con transparencia diferente. La explicación de Bacon, como advertimos en el artículo, subraya la importancia de acudir a un cierto principio de conservación pero no hace ningún esfuerzo por conectar dicho principio con una ley cuantitativa. Vimos que Bacon vacila entre un principio de economía y un principio de conservación. Si adoptamos el principio de economía, podemos explicar por qué la luz se pliega a la normal cuando pasa a un medio de mayor densidad. Pero no podemos explicar por qué la luz se aleja de la normal cuando pasa a un medio de menor densidad. El principio de conservación salva la dificultad señalada. Pecham, por su parte, sugiere que en el horizonte de la explicación debía hallarse una ley cuantitativa precisa. Aunque Pecham formula una reserva valiosa en relación con el finalismo que se insinúa en el intento de Bacon, no logra ofrecer una explicación mejor, toda vez que no logra precisar la ley cuantitativa que debe orientar la exploración cualitativa. En ese orden de ideas, la explicación de Bacon, a pesar de su finalismo, no tiene el semblante de una explicación frustrada, como ocurre en el caso de Pecham. Witelo, por su parte, hace esfuerzos por hallar una ley cuantitativa que se soporte en datos experimentales. Los datos, por sí mismos, no pueden mostrar el camino que ha de conducir a la ley buscada. De hecho se requiere de una idea directriz que permita, aunque sea a la manera de conjetura, ofrecer una posible organización en los datos suministrados por el experimento. Witelo introduce, en su explicación cualitativa, una participación activa del universo en su conjunto. Se trata de una participación que opera en la dirección normal a la interface entre los dos medios. Siglos más tarde, Newton trató de ofrecer una explicación a la refracción apoyado en una teoría corpuscular de la naturaleza de la luz, en su teoría introdujo una acción o fuerza que debía operar en la interface de los dos medios en una dirección perpendicular a la misma. 


\section{Bibliografía}

AlHacen (2001). Ver Smith, M. (2001).

AlHacen (2006). Ver Smith, M. (2006).

AlHacen (2008). Ver Smith, M. (2008).

Alhacen (2010). Ver Smith, M. (2010).

Aristóteles (1978). Acerca del alma. Madrid, Editorial Gredos. Traducción al español de Tomas Calvo Martínez.

ArIstóteles (1987). Acerca de la sensación. En Tratados breves de historia natural.

Madrid, Editorial Gredos. Traducción al español de Ernesto La Croce y Alberto Bernabé Pajares.

ArIstóteles (1987a). Acerca de la generación y la corrupción. Madrid, Editorial

Gredos. Traducción al español de Ernesto La Croce y Alberto Bernabé Pajares. Aristóteles (1987b). Acerca de los ensueños. En Tratados breves de historia natural. Madrid, Editorial Gredos. Traducción al español de Ernesto La Croce y

Alberto Bernabé Pajares.

Aristóteles (1994). Metafisica. Madrid, Editorial Gredos. Traducción al español de Tomás Calvo Martínez.

Bacon, Roger (1928). Opus Majus. Philadelphia, University of Pennsylvania Press.

Edición a cargo de Robert Belle Burke.

BACon, Roger (1996). Perspectiva. Ver D. Lindberg (1996).

BACon, Roger (1998). De multiplicatione specierum. Ver D. Lindberg (1998).

ClegG, Brian (2003). The first scientist. A life of Roger Bacon. New York, Carroll \& Graff Publishers.

Crombie, A. C. (1953). Robert Grosseteste and the origins of experimental science 1100-1700. Oxford, Oxford at the Clarendon Press.

Descartes, R. (1988). Euvres philosophiques. París, Clasiques Garnier, edición preparada y comentada por Ferdinand Alquié, 3 volúmenes.

EASTwOod, Bruce S. (1967), "'Cuantitative' Law of Refraction: A Chapter in the History of Non-experimental Science", en Journal of the History of Ideas, Vol. 28, N0. 3, pp. 403-414.

Grant, Edward (editor). (1974). A Source Book in Medieval Science. Cambridge, Mass, Harvard University Press.

Grosseteste, R. (1974). “Concerning Lines, Angles, and Figures", en E. Grant (1974), pp. 385-388.

Grosseteste, R. (1974a). “On the Rainbow”, en E. Grant (1974), pp. 388-391.

Grosseteste, R. (1978). On Light. Milwaukee, Marquette University Press. Traducción del latín de Clare C. Riedl.

Grosseteste, R. (1982). Hexaëmeron. Londres, The Oxford University Press. Edición a cargo de Richard C. Dales y Servus Gieben. Versión en inglés: Grosse- 
TESTE, R. (1996). On the Six Days of Creation. Oxford, Oxford University Press. Traducción del Hexaëmeron por C. F. J. Martin.

Hackett, Jeremiah (1997). "Roger Bacon: his life, career and works", en J. Hackett (1997b), pp. 7-23.

HACKETT, Jeremiah (1997a). "Roger Bacon on Scientia Experimentalis", en J. Hackett (1997b), pp. 277-315.

Hackett, Jeremiah (1997b) (edit.). Roger Bacon \& the Sciences. Commemorative Essays. Leiden, Brill.

Kepler, Johannes (2000). Optics: Paralipomena to Witelo \& Optical Part of Astronomy. Santa Fe: Green Lion Press, traducción de William H. Donahue.

LindBerg, David C. (1968). "The cause of refraction in medieval optics". The British Society for the History of Science, Vol. 4, No. 1, pp. 23-38.

Lindberg, David C. (1970). John Pecham and the Science of Optics, traducción y edición crítica del Perspectiva Communis de John Pecham. Madison, The University of Wisconsin Press.

LindBerg, David C. (1971). "Lines of Influence in Thirteenth-Century Optics: Bacon, Witelo, and Pecham”. Speculum, Vol. 46, No. 1, pp. 66-83.

LindBerg, David C. (1996). Roger Bacon and the origins of Perspectiva in the middle ages. A critical edition and English translation of Bacon's Perspectiva. Oxford, Clarendon Press.

LindBerg, David C. (1997). "Light, Vision and the Universal Emanation of Force”, en J. Hacket (1997), pp. 243-275.

LindBerg, David C. (1998). Roger Bacon's Philosophy of Nature. A critical edition, with English translation of De multiplication specierum and De speculis comburentibus. South Bend (Ind), St. Augustine's Press.

Michaud-Quantin, Pierre (1970). Études sur le vocabulaire philosophique du moyen âge. Roma, Ed. Dell'Ateneo.

Pecham, John (1970). Perspectiva communis. Ver D. Lindberg (1970).

Ptolomeo (1996). Ver Smith M. (1996).

Raizman-Kedar, Yael (2009). "The Intellect Naturalized: Roger Bacon on the Existence of Corporeal Species within the Intellect”. Early Science and Medicine 14, pp. 131-157.

RAscheD, Roshdi (1990). "A pioneer in Anaclastics: Ibn Sahl on Burning Mirrors and Lenses". Isis, Vol. 81, No. 3, pp. 464-491.

Salmon, Wesley (1998). Causality and Explanation. New York, Oxford University Press.

Sidelko, Paul (1996). "The comdemnation of Roger Bacon", en Journal of Medieval History, Vol. 22, No. 1, pp. 69-81.

Smith, A. Mark (1983). Witelonis perspectivae liber quintus. Book $V$ of Witelo's Perspectiva. Wroclaw, Studia Copernicana XXIII, The Polish Academy of Science Press. 
Sмith, A. Mark (1996). Ptolemy's Theory of Visual Perception. Philadelphia, The American Philosophical Society. Traducción al inglés y edición preparada por A. Mark Smith.

Smith, A. Mark (2001). Alhacen's Theory of visual perception. Philadelphia, American Philosophical Society. Traducción al inglés con comentarios de los tres primeros libros del De Aspectibus de Alhacén, preparado por Mark Smith. 2 volúmenes.

Sмiтн, A. Mark (2006). Alhacen on the principles of reflection. Philadelphia, American Philosophical Society. Traducción al inglés con comentarios de los libros 4 y 5 del De Aspectibus de Alhacén, preparado por Mark Smith. 2 volúmenes.

Sмітн, A. Mark (2008). Alhacen on image-formation and distortion in mirrors. Philadelphia, American Philosophical Society. Traducción al inglés con comentarios del libro 6 del De Aspectibus de Alhacén, preparado por Mark Smith. 2 volúmenes.

Sмith, A. Mark (2010). Alhacen on Refraction. Philadelphia, American Philosophical Society. Traducción al inglés con comentarios del libro 7 del De Aspectibus de Alhacén, preparado por Mark Smith, 2 volúmenes.

Thorndike, Lynn (1916). "The True Roger Bacon, I", en The American Historical Review, Vol. 21, No. 2, pp. 237-257.

Thorndike, Lynn (1916a). "The True Roger Bacon, II”, en The American Historical Review, Vol. 21, No. 3, pp. 468-480.

Unguru, Sabetai (1972). "Witelo and Thirteenth-Century Mathematics: An Assessment of his Contibutions". Isis, Vol. 63, No. 4, pp. 496-508.

Unguru, Sabetai (1977). Witelonis perspectivae liber primus. Book I of Witelo's Perspectiva. Wroclaw, Studia Copernicana XV, The Polish Academy of Science Press.

Unguru, Sabetai (1991). Witelonis perspectivae liber secundus et liber tertius. Books II and IIII of Witelo's Perspectiva. Wroclaw, Studia Copernicana XXVIII, The Polish Academy of Science Press.

Witelo (1977). Ver S. Unguru (1977).

Witelo (1983). Ver A. M. Smith (1983).

Witelo (1991). Ver S. Unguru (1991).

Carlos Alberto Cardona Suárez

Universidad del Rosario (Bogotá-Colombia)

Escuela de Ciencias Humanas

carlos.cardona@urosario.edu.co 